\title{
BMJ Open Survival after bone metastasis by primary cancer type: a Danish population-based cohort study
}

\author{
Elisabeth Svensson, ${ }^{1,2}$ Christian F Christiansen, ${ }^{1}$ Sinna P Ulrichsen, ${ }^{1}$ \\ Mikael R Rørth, ${ }^{3}$ Henrik T Sørensen ${ }^{1}$
}

To cite: Svensson E, Christiansen CF, Ulrichsen SP, et al. Survival after bone metastasis by primary cancer type: a Danish populationbased cohort study. BMJ Open 2017;7:e016022. doi:10.1136/ bmjopen-2017-016022

- Prepublication history and additional material for this paper are available online. To view please visit the journal online (http://dx.doi.org/10.1136/ bmjopen-2017-016022)

Received 18 January 2017 Revised 2 June 2017 Accepted 31 July 2017

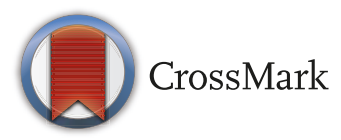

${ }^{1}$ Department of Clinical Epidemiology, Institute of Clinical Medicine, Aarhus University, Aarhus, Denmark

${ }^{2}$ Department of Epidemiology and Biostatistics, The Danish Clinical Registries, Aarhus, Denmark

${ }^{3}$ Department of Oncology, Copenhagen University Hospital (Rigshospitalet), Copenhagen, Denmark

Correspondence to Dr Elisabeth Svensson; elisabeth.svensson@rkkp.dk

\section{ABSTRACT}

Objective In the 10 most common primary types with bone metastases, we aimed to examine survival, further stratifying on bone metastases only or with additional synchronous metastases.

Methods We included all patients aged 18 years and older with incident hospital diagnosis of solid cancer between 1994 and 2010, subsequently diagnosed with BM until 2012. We followed patients from date of bone metastasis diagnosis until death, emigration or 31 December 2012, whichever came first. We computed 1-year, 3-year and 5 -year survival (\%) and the corresponding $95 \% \mathrm{Cls}$ stratified on primary cancer type. Comparing patients with bone metastasis only and patients with other synchronous metastases, we estimated crude and adjusted HRs and corresponding $95 \% \mathrm{Cl}$ for mortality.

Results We included 17251 patients with bone metastasis. The most common primary cancer types with bone metastasis were prostate (34\%), breast (22\%) and lung (20\%). One-year survival after bone metastasis diagnosis was lowest in patients with lung cancer $(10 \%$, 95\% Cl 9\% to 11\%) and highest in patients with breast cancer $(51 \%, 50 \%$ to $53 \%)$. At 5 years of follow-up, only patients with breast cancer had over $10 \%$ survival $(13 \%$, $11 \%$ to $14 \%$ ). The risk of mortality was increased for the majority of cancer types among patients with bone and synchronous metastases compared with bone only (adjusted relative risk 1.29-1.57), except for cervix, ovarian and bladder cancer.

Conclusions While patients with bone metastases after most primary cancers have poor survival, one of ten patients with bone metastasis from breast cancer survived 5 years.

\section{INTRODUCTION}

Bone is the third most common site of metastatic disease in patients with cancer. ${ }^{12}$ Bone metastases occur in every cancer type, but are most common in patients with cancers of the breast, prostate or lung. ${ }^{2-4}$ Such metastases are often painful and can cause considerable morbidity, ${ }^{245}$ including a range of skeletal related events, ${ }^{6}$ and is associated with substantial use of hospital resources. ${ }^{78}$

Population-based reports on length of survival after bone metastases from many

\section{Strengths and limitations of this study}

Strengths of this study include its large size and population-based design.

- The high-quality Danish medical databases provide complete hospital contact and follow-up of all patients, thereby limiting the risk of referral and diagnostic bias.

- Although the coding is reasonable accurate, the proportions of patients with bone metastases are likely to be underestimated.

- We used the date of hospital diagnosis of bone metastases as registered in the Danish National Patient Registry, this date may not be the same as the first evidence of metastasis.

- We only included synchronous metastases diagnosed prior to the bone metastasis, thus, the figure of $90 \%$ of patients having bone metastases only, reflects that bone was the first location of metastases.

primary cancer types are lacking. In patients with breast, prostate and renal cancer, the reported median survival ranges from 12 to 33 months for patients with bone metastases, ${ }^{9-14}$ and survival increases with longer time between primary diagnosis and such metastases. ${ }^{15}$ On the other hand, survival is low for patients with primary lung cancer and bone metastases, 1-year survival ranging from $9.5 \%$ to $12 \% .^{1617}$

Previous research has suggested that survival among patients with bone metastases is associated with tumour and other disease characteristics. In a clinical setting, having other synchronous metastases in addition to bone metastasis was associated with impaired prognosis compared with bone metastasis only in patients with primary gynaecological or prostate cancer. ${ }^{11} 18$ For other cancer types, this information is not available in a population-based setting. We hypothesise that survival for other cancers will follow the above-mentioned pattern, being better when no synchronous metastases are observed. 
Thus, in the 10 most common solid cancers with bone metastasis, we aimed to estimate survival, and to compare mortality among patients with bone metastasis only with mortality of patients who were diagnosed with additional other synchronous metastases.

\section{MATERIAL AND METHODS \\ Study population}

We conducted this population-based cohort study in Denmark, with about 5.6 million inhabitants, based on a linkage of prospectively collected data from Danish medical registries. Denmark is a welfare state with tax-funded universal access to healthcare, providing primary and secondary care without out-of-pocket expenses and partial reimbursement for most prescribed medications. Individual-level data from all Danish registries can be linked via the unique personal identifier, the CPR number, assigned at birth, registered in the Danish Civil Registration system (CRS).$^{19}$

\section{Cancer patients with bone metastasis}

We included all adult (over 18 years of age) residents of Denmark diagnosed with cancer in the Danish Cancer Registry from 1 January 1994 to 31 December 2010, and with a diagnosis of bone metastasis registered in the Danish National Patient Registry (DNPR) on or after the date of primary cancer diagnosis until 31 December $2012 .{ }^{20}$ DNRP holds discharge diagnoses from all inpatient admissions to Danish hospitals since 1977 and hospital outpatient clinic diagnoses since 1995. For each visit, the DNPR includes information on admission and discharge, procedures and up to 20 diagnoses. Since 1994, the diagnostic information has been coded according to the International Classification of Diseases, 10th Revision. All diagnostic codes are given in the online supplementary appendix.

We stratified patients with bone metastasis to bone metastasis at the time of primary cancer diagnosis or more than 3 months after primary cancer diagnosis. Cases of bone metastasis diagnosed more than 3 months after cancer diagnosis were further stratified into bone metastasis only (no other metastasis) or bone with other synchronous metastases, defined as patients having other metastases prior to diagnosis of bone metastases.

\section{Covariates}

From the DNPR, we collected information on the 19 major non-psychiatric comorbidities in the Charlson Comorbidity Index (CCI) prior to diagnosis of bone metastasis, ${ }^{21}$ using a modified version where any tumour, leukaemia, lymphoma and metastatic solid tumour is excluded in the calculation. Based on the CCI score, we defined three comorbidity levels: low (score of 0 ), medium (score of 1-2) and high (score of 3+).

\section{Follow-up}

Patients were followed from diagnosis of bone metastasis to date of death, emigration or 31 December 2012, whichever came first. Information on vital status (alive, dead, emigration) was obtained from the Danish CRS. ${ }^{19}$ The CRS contains electronic records of age, gender, vital status and place of residence (address) for the entire Danish population since 1968, and is updated daily.

This study was approved by the Danish Data Protection Agency (Record Nr. 1-16-02-1-08). As this registry-based study did not involve patient contact, no separate permission from the Danish Scientific Ethics Committee was required, according to Danish legislation.

\section{Statistical analysis}

We examined the 10 most common primary cancer types with bone metastases. For the three most common types: breast, prostate and lung, we investigated the distribution of bone metastases, stratified on bone metastasis presence at the time of primary cancer diagnosis or more than 3 months after diagnosis. We computed 1-year, 3-year and 5 -year survival with corresponding 95\% CIs using the Kaplan-Meier methods for all bone metastasis after all cancer types.

We further stratified on bone metastases only and bone plus other synchronous metastases, restricted to patients diagnosed with bone metastases more than 3 months after primary cancer diagnosis. We calculated the median age at bone metastasis diagnosis and median time from cancer diagnosis to bone metastasis for each cancer type and computed Kaplan-Meier survival curves for this stratification. We calculated the percentage of patients with bone metastases only, compared with bone plus other synchronous metastases at the time of bone metastasis diagnosis. By Cox regression, we estimated HRs for death and the corresponding 95\% CI separately for each primary cancer type, comparing bone metastases only with bone and additional metastases. The proportional hazard assumption was fulfilled. The HR was adjusted for age, gender, CCI score and period of diagnosis.

We used SAS statistical software, V.9.2 (SAS Institute), for all statistical analyses.

\section{RESULTS}

In the 10 most common primary cancers with bone metastasis, we identified 17251 patients diagnosed between 1994 and 2010, followed up for bone metastasis until the end of 2012. Prostate, breast and lung cancer were the most frequent primary cancer types, accounting for $34 \%$, $22 \%$ and $20 \%$ of patients with bone metastasis, respectively. In table 1 , the distribution of bone metastasis by cancers of the lung, prostate and breast are given over time. For breast and prostate cancer, the proportion developing bone metastasis is rather stable over time, taken into account a shorter follow-up for the last time period under investigation. However, for lung cancer there seems to be a slight increase in proportion over time. 
Table 1 Patients who develop bone metastasis by all breast, lung and prostate cancers over time, overall and stratified into bone metastasis at the time of primary cancer diagnosis or more than 3 months after primary diagnosis

\begin{tabular}{|c|c|c|c|c|c|c|c|c|}
\hline \multirow[b]{3}{*}{ Cancer type } & \multirow{3}{*}{$\begin{array}{l}\text { Year of cancer } \\
\text { diagnosis }\end{array}$} & \multirow{3}{*}{$\begin{array}{l}\text { Total number } \\
\text { patients with } \\
\text { cancer } \\
\mathbf{n}\end{array}$} & \multicolumn{6}{|c|}{ Patients who develop bone metastasis } \\
\hline & & & \multicolumn{2}{|l|}{ Total } & \multicolumn{2}{|c|}{$\begin{array}{l}\text { At primary cancer } \\
\text { diagnosis }\end{array}$} & \multicolumn{2}{|c|}{$\begin{array}{l}\text { More than } 3 \text { months } \\
\text { after primary diagnosis }\end{array}$} \\
\hline & & & $\mathbf{n}$ & $\%$ & $n$ & $\%$ & $n$ & $\%$ \\
\hline \multirow[t]{4}{*}{ Lung } & 1994-1997 & 13713 & 445 & 3 & 291 & 2 & 154 & 1 \\
\hline & $1998-2001$ & 14419 & 633 & 4 & 333 & 2 & 300 & 2 \\
\hline & 2002-2006 & 19504 & 1188 & 6 & 755 & 4 & 433 & 2 \\
\hline & $2007-2010$ & 17270 & 1137 & 7 & 785 & 5 & 352 & 2 \\
\hline \multirow[t]{4}{*}{ Breast } & 1994-1997 & 13623 & 936 & 7 & 143 & 1 & 793 & 6 \\
\hline & 1998-2001 & 15145 & 1001 & 7 & 172 & 1 & 829 & 5 \\
\hline & 2002-2006 & 20348 & 1223 & 6 & 314 & 2 & 909 & 4 \\
\hline & 2007-2010 & 19893 & 629 & 3 & 236 & 1 & 393 & 2 \\
\hline \multirow[t]{4}{*}{ Prostate } & 1994-1997 & 6041 & 1034 & 17 & 308 & 5 & 726 & 12 \\
\hline & 1998-2001 & 7774 & 1602 & 21 & 352 & 5 & 1250 & 16 \\
\hline & 2002-2006 & 13588 & 2181 & 16 & 652 & 5 & 1529 & 11 \\
\hline & $2007-2010$ & 15454 & 1124 & 7 & 325 & 2 & 799 & 5 \\
\hline
\end{tabular}

\section{Survival}

Survival after diagnosis of bone metastasis (all) varied widely by cancer type (table 2). One-year survival after bone metastasis was lowest in patients with lung cancer $(10 \%, 95 \%$ CI $9 \%$ to $11 \%)$ and highest in patients with breast cancer $(51 \%, 95 \%$ CI $50 \%$ to $53 \%)$. Three-year survival ranged from $2 \%$ for lung cancer (95\% CI 1 to 2), $12 \%(96 \%$ CI $11 \%$ to $13 \%$ ) for prostate to $25 \%$ (95\% CI $23 \%$ to $26 \%$ ) for breast cancer. At 5 years of follow-up, only patients with breast cancer among the solid tumours had over $10 \%$ survival $(13 \%, 95 \%$ CI $11 \%$ to $14 \%)$.

Bone metastasis only versus bone metastasis with other synchronous metastases

Median time from primary cancer diagnoses to bone metastasis, restricted to patients without bone metastasis within 3 months of being diagnosed with the primary cancer ranged from close to 1year (eg, lung cancer,

Table 2 One-year, 3-year and 5-year survival estimates with 95\% Cl after bone metastasis diagnosis (all) by primary cancer type

\section{1-year survival \% $(95 \% \mathrm{Cl}) \quad 3$-year survival $\%(95 \% \mathrm{Cl}) \quad$ 5-year survival $\%(95 \% \mathrm{Cl})$}

\begin{tabular}{|c|c|c|c|}
\hline \multicolumn{4}{|l|}{ Digestive organs } \\
\hline Colon* & 21 (18 to 25$)$ & 7 (5 to 10$)$ & 3 (2 to 5$)$ \\
\hline Rectum & 22 (18 to 26$)$ & 3 (2 to 5$)$ & 2 (1 to 3$)$ \\
\hline Lung & 10 (9 to 11$)$ & 2 (1 to 2$)$ & $1(0.5$ to 1$)$ \\
\hline Malignant melanoma & 17 (12 to 22$)$ & $6(4$ to 10$)$ & 5 (3 to 8) \\
\hline \multicolumn{4}{|l|}{ Female genital organs } \\
\hline Cervix & 18 (11 to 28$)$ & 6 (2 to 14$)$ & $2(0$ to 7$)$ \\
\hline Ovary & 33 (21 to 44$)$ & 15 (7 to 25$)$ & 8 (3 to 18) \\
\hline \multicolumn{4}{|l|}{ Male genital organs } \\
\hline Prostate & 35 (34 to 37 ) & 12 (11 to 13 ) & 6 (5 to 7 ) \\
\hline
\end{tabular}

*Including colonrectosigmoid. 
Table 3 Median age (years) at bone metastasis diagnosis and median time (days) since primary cancer to bone metastasis by primary cancer type stratified on bone metastasis only or bone metastasis plus other synchronous metastasis. Patients with bone metastasis at or within 3 months of primary cancer diagnosis were excluded

\begin{tabular}{|c|c|c|c|c|}
\hline & $\mathbf{N}$ & $\begin{array}{l}\text { Median age, years, } \\
\text { at diagnosis, (IQR) }\end{array}$ & $\begin{array}{l}\text { Median time, days, from } \\
\text { primary cancer diagnosis to } \\
\text { bone met only (IQR) }\end{array}$ & $\begin{array}{l}\text { Median time, days, from } \\
\text { primary cancer to Bone } \\
\text { metastasis+other synchronous } \\
\text { metastases (IQR) }\end{array}$ \\
\hline \multicolumn{5}{|l|}{ Digestive organs } \\
\hline Colon (incl rectosig.) & 355 & $68(60-76)$ & 748 (341-1429) & $778(495-1216)$ \\
\hline Rectum & 349 & $68(60-76)$ & $870(414-1426)$ & $1193(500-1806)$ \\
\hline \multicolumn{5}{|l|}{ Respiratory organs } \\
\hline Lung & 1239 & $66(59-73)$ & $295(175-564)$ & $279(167-541)$ \\
\hline Malignant melanoma & 225 & $64(61-73)$ & $784(437-1703)$ & $961(454-1872)$ \\
\hline Breast & 2924 & $63(54-72)$ & $1246(336-2151)$ & $1432(451-2309)$ \\
\hline \multicolumn{5}{|l|}{ Female genital organs } \\
\hline Cervix & 64 & $52(45-65)$ & $723(473-1520)$ & 574 (491-1229) \\
\hline Ovary & 54 & $62(51-68)$ & $784(444-1405)$ & 987 (463-2572) \\
\hline \multicolumn{5}{|l|}{ Male genital organs } \\
\hline Prostate & 4304 & $74(68-80)$ & 767 (411-1422) & 748 (403-1352) \\
\hline \multicolumn{5}{|l|}{ Urinary organs } \\
\hline Kidney & 346 & $66(58-73)$ & $545(243-1306)$ & 668 (60-1599) \\
\hline Bladder & 438 & $71(64-77)$ & $463(260-1027)$ & 610 (336-999) \\
\hline
\end{tabular}

279-295 days) to several years (eg, breast cancer, about 3.5-4 years) (table 3 ). Median time to bone metastasis was comparable for bone metastasis only and bone metastasis with synchronous metastasis.

For all patients with bone metastasis, except malignant melanoma, around $90 \%$ of patients had only such metastasis (table 4). Survival curves for bone metastasis after specific primary cancers, with and without the presence of other metastases, are presented in figure 1 . Table 4 shows the Cox regression comparing mortality for patients with and without additional metastases at the time of bone metastasis diagnosis. The crude risk for mortality is increased for patients with synchronous metastasis compared with bone metastasis only, except for ovary, cervix and bladder cancer, with crude HR ranging from 1.3 (95\% CI 1.0 to 1.6) for malignant melanoma to $\mathrm{HR}=1.6(95 \%$ CI 1.4 to 1.8$)$ for prostate cancer (table 4) and did not change considerably when adjusted for age, gender, comorbidity and year of diagnosis.

\section{DISCUSSION}

In this large heterogeneous cohort of 17251 patients with bone metastasis in the 10 specific primary cancer types where bone metastases are most commonly observed, we find that the prognosis after diagnosis of bone metastasis is depending on primary cancer type. Furthermore, the prognosis is poorer when other metastases are present at the time of bone metastasis diagnosis.

Strengths of this study include its large size and population-based design, made possible through access to high-quality Danish medical databases providing a complete hospital contact and follow-up of all patients, thereby limiting the risk of referral and diagnostic bias. Our data derive from a wide range of unselected patients in real life and the generalisability may be transferrable to other population-based settings.

Our registry-based population approach also introduces some limitations. The validity of our findings depends on the completeness and the accuracy of reporting to the DNPR. The diagnoses registered in the DNPR as compared with a review of medical records have a high specificity, but the completeness was low, primary related to metastases without symptoms. ${ }^{22}$ Thus, although the coding is reasonably accurate, the proportions of patients with bone metastases are likely to be underestimated. ${ }^{22}$ It is possible that in lieu of other metastases, such as lung metastases, additional bone metastasis would to a lesser extent be recorded, this non-random misclassification would possibly influence the estimates, resulting in an even more increased risk of mortality among patients with additional metastases compared with bone only. On the other hand, if patients with other synchronous metastases do not have their bone metastasis recorded, they would not be included in the study, and therefore lead to selection bias, and possibly a lower mortality among the included patients. We only included synchronous metastases diagnosed prior to the bone metastasis, thus the figure of $90 \%$ of patients having bone metastasis only, reflects that bone metastasis were located first, and that the patients may have developed other subsequent 
Table 4 HRs and corresponding 95\% Cls for mortality after bone metastasis, comparing patients with bone metastasis only and patients with additional synchronous metastases

\begin{tabular}{|c|c|c|c|c|c|}
\hline Primary cancer & & $\mathbf{N}(\%)$ & $\begin{array}{l}\text { Median survival } \\
\text { time (days) }\end{array}$ & HR $(95 \% \mathrm{Cl})$ & Adjusted* HR $(95 \% \mathrm{Cl})$ \\
\hline \multirow[t]{2}{*}{ Colon cancer } & Bone metastasis only & $452(91)$ & 105 & 1.0 & 1.0 \\
\hline & $\begin{array}{l}\text { Bone+other synchronous } \\
\text { metastases }\end{array}$ & $47(9)$ & 95 & 1.38 (1.02 to 1.87$)$ & 1.48 (1.09 to 2.03$)$ \\
\hline \multirow[t]{2}{*}{ Rectum cancer } & Bone metastasis only & $361(90)$ & 114 & 1.0 & 1.0 \\
\hline & $\begin{array}{l}\text { Bone+other synchronous } \\
\text { metastases }\end{array}$ & $39(10)$ & 79 & 1.47 (1.06 to 2.05$)$ & 1.44 (1.03 to 2.03$)$ \\
\hline \multirow[t]{2}{*}{ Lung cancer } & Bone metastasis only & 2871 (84) & 74 & 1.0 & 1.0 \\
\hline & $\begin{array}{l}\text { Bone+other synchronous } \\
\text { metastases }\end{array}$ & $532(16)$ & 61 & 1.20 (1.10 to 1.32$)$ & 1.27 (1.16 to 1.40$)$ \\
\hline \multirow{2}{*}{$\begin{array}{l}\text { Malignant } \\
\text { melanoma }\end{array}$} & Bone metastasis only & $172(64)$ & 95 & 1.0 & 1.0 \\
\hline & $\begin{array}{l}\text { Bone+other synchronous } \\
\text { metastases }\end{array}$ & $97(36)$ & 75 & 1.26 (0.97 to 1.63$)$ & 1.29 (0.99 to 1.69$)$ \\
\hline \multirow[t]{2}{*}{ Breast cancer } & Bone metastasis only & $3268(86)$ & 377 & 1.0 & 1.0 \\
\hline & $\begin{array}{l}\text { Bone+other synchronous } \\
\text { metastases }\end{array}$ & $521(14)$ & 170 & $1.42(1.28$ to 1.57$)$ & 1.47 (1.33 to 1.63$)$ \\
\hline \multirow[t]{2}{*}{ Cervix cancer } & Bone metastasis only & $67(91)$ & 98 & 1.0 & 1.0 \\
\hline & $\begin{array}{l}\text { Bone+other synchronous } \\
\text { metastases }\end{array}$ & $7(9)$ & 46 & 1.06 (0.48 to 2.33$)$ & $1.00(0.42$ to 2.38$)$ \\
\hline \multirow[t]{2}{*}{ Ovarian cancer } & Bone metastasis only & $54(83)$ & 170 & 1.0 & 1.0 \\
\hline & $\begin{array}{l}\text { Bone+other synchronous } \\
\text { metastases }\end{array}$ & $11(17)$ & 129 & 1.12 (0.56 to 2.23$)$ & 1.08 (0.51 to 2.29$)$ \\
\hline \multirow[t]{2}{*}{ Prostate cancer } & Bone metastasis only & $5726(96)$ & 210 & 1.0 & 1.0 \\
\hline & $\begin{array}{l}\text { Bone+other synchronous } \\
\text { metastases }\end{array}$ & $215(4)$ & 109 & 1.55 (1.35 to 1.78$)$ & 1.57 (1.36 to 1.80$)$ \\
\hline \multirow[t]{2}{*}{ Kidney cancer } & Bone metastasis only & $609(77)$ & 182 & 1.0 & 1.0 \\
\hline & $\begin{array}{l}\text { Bone+other synchronous } \\
\text { metastases }\end{array}$ & $186(23)$ & 105 & 1.33 (1.12 to 1.58$)$ & 1.41 (1.18 to 1.69$)$ \\
\hline \multirow{2}{*}{$\begin{array}{l}\text { Urinary bladder } \\
\text { cancer }\end{array}$} & Bone metastasis only & $513(94)$ & 68 & 1.0 & 1.0 \\
\hline & $\begin{array}{l}\text { Bone+other synchronous } \\
\text { metastases }\end{array}$ & $33(6)$ & 56 & 1.14 (0.79 to 1.65$)$ & $1.22(0.84$ to 1.77$)$ \\
\hline
\end{tabular}

*Adjusted by gender, age, Charlson Comorbidity Index Score and period of diagnosis.

metastases not included in our analyses. Furthermore, we did not take into account the patients who developed a second primary cancer, which again might experience poorer survival. We here assumed that the bone metastasis arose from the first cancer. Finally, we used the date of hospital diagnosis of bone metastasis as registered in the DNPR, and thus, the date may not be the same as the first evidence of metastasis, which may also explain why median survival is shorter than reported by others.

This study corroborates previous research findings regarding prognosis after bone metastasis. ${ }^{10-12}$ As noted by Ibrahim et al, most bone metastasis are secondary to breast, prostate and lung cancer. ${ }^{5}$ Generally, the 1-year survival rates observed in the present study are lower than other clinical based studies. ${ }^{1112}$ For example, Drzymalski et al estimated a 1-year survival of $73 \%$ based on a study on patients in the Prostate Clinical Research Information System at the Dana-Farber Cancer Institute. ${ }^{11}$ It is possible that in countries with high levels of screening for prostate cancer, the bone metastasis may be detected earlier via elevated PSA screening, or with a higher proportion of castration naïve prostate cancers, and therefore have a better prognosis than observed here. For breast cancer, patients with hormone receptor positive cancers can have a long survival even with bone metastasis. However, receptor status is not known in this study. Nonetheless, most other reports come from specialised cancer treatment facilities, thus conceivably encompass selected groups of patients and accordingly suffer from bias when compared with results of population-based studies applied to the real-life situation. 

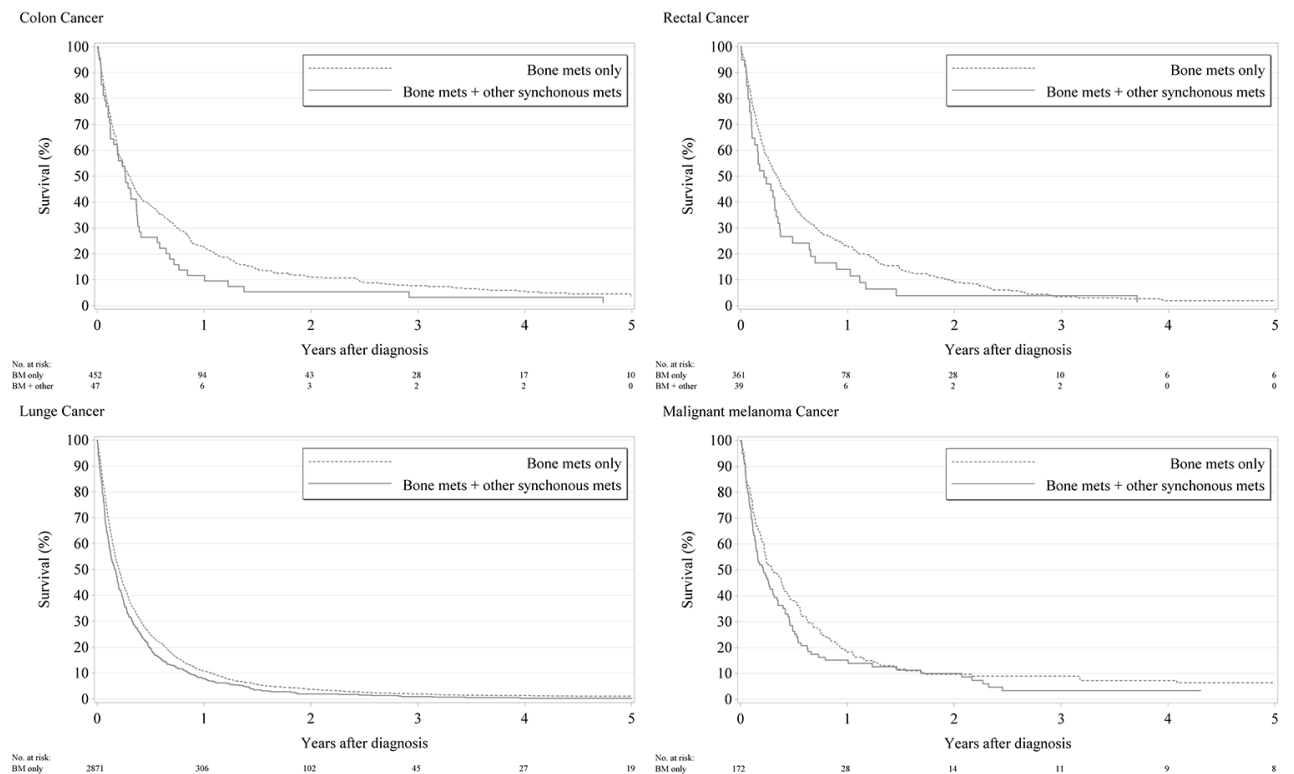

Malignant melanoma Cancer
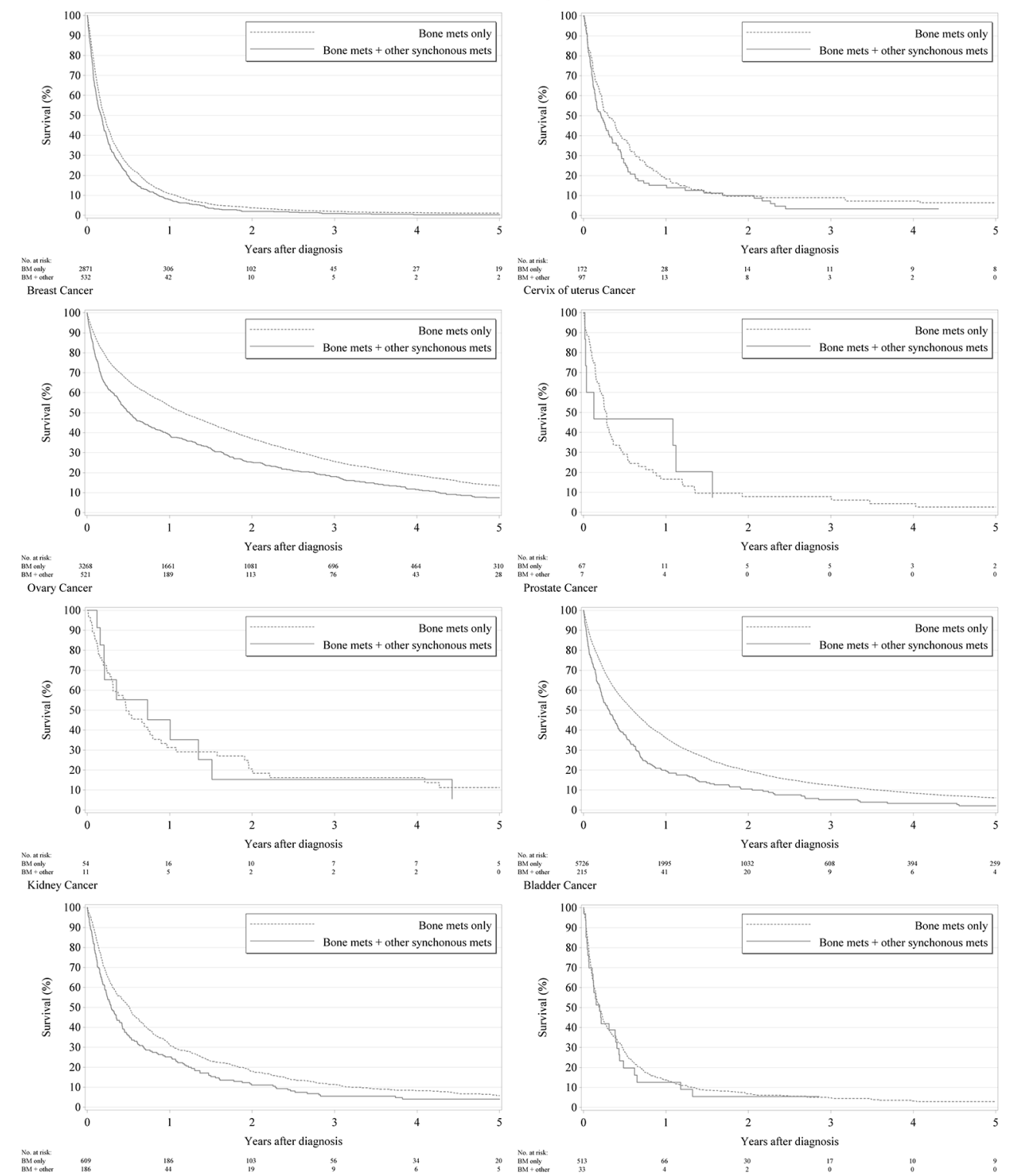

Figure 1 Cumulative survival comparing bone metastasis only with bone metastasis and other synchronous metastases.

In accordance with our hypothesis and previous findings, ${ }^{11} 18$ having other metastases impaired prognosis after bone metastasis diagnosis. Additional metastases might be indicative of a more aggressive primary tumour. However, since the patients with other synchronous metastases, in addition to bone, may have had their other metastasis for some time, it is not surprising that their mortality is higher, simply because a longer time had elapsed after the primary diagnosis. Nonetheless, as time from diagnosis of primary cancer to bone metastasis can be regarded as an intermediate variable, we have not controlled for this in an adjusted analysis.

Unfortunately, we did not have individual-level information about the primary treatments and the specific bone-targeted therapy eventually received by the patients. We investigated a longtime course, and thus new treatments implemented during the study period can confound the observed prognosis. Further studies are warranted 
on incidence and survival of patients with bone metastasis over time with respect to the bone-targeted therapy for the different cancer types, to examine the influence clinical options may have on prognosis. Furthermore, a detailed examination of the natural history of the patients with bone metastasis, including a detailed description of skeletal related events, is beyond the scope of this article, but also warrants further examination. Another area warranting further investigation is whether the outcome differs for the different solid primary tumours according to osteolytic versus osteoblastic bone metastases. Nonetheless, as this is a population-based study covering all of Denmark, the generalisability of the study applies.

In conclusion, this population-based registry study with complete follow-up shows that there is a significant proportion of patients with long-term survival with bone metastasis in selected malignant diseases, such as breast cancer.

Acknowledgements We thank John Acquavella for constructive comments to the article.

Contributors CFC and HTS conceived the idea for the study and developed the study concept and design together with ES and SPU performed the statistical analysis. All authors contributed to the interpretation, drafting and revision of the manuscript, approved its final version, and agreed to be accountable for all aspects of the work.

Funding Funding was provided by a research grant to Aarhus University by Amgen Inc. Department of Clinical Epidemiology, Aarhus University Hospital, Aarhus, Denmark receives funding from various companies (including Amgen Inc) as research grants to and administered by Aarhus University.

Competing interests None declared.

Provenance and peer review Not commissioned; externally peer reviewed. Data sharing statement No additional data are available.

Open Access This is an Open Access article distributed in accordance with the Creative Commons Attribution Non Commercial (CC BY-NC 4.0) license, which permits others to distribute, remix, adapt, build upon this work non-commercially, and license their derivative works on different terms, provided the original work is properly cited and the use is non-commercial. See: http://creativecommons.org/ licenses/by-nc/4.0/

(C) Article author(s) (or their employer(s) unless otherwise stated in the text of the article) 2017. All rights reserved. No commercial use is permitted unless otherwise expressly granted.

\section{REFERENCES}

1. Nielsen OS, Munro AJ, Tannock IF. Bone metastases: pathophysiology and management policy. J Clin Oncol 1991;9:509-24.
2. Ibrahim T, Mercatali L, Amadori D. Bone and cancer: the osteoncology. Clin Cases Miner Bone Metab 2013;10:121-3.

3. Ibrahim T, Mercatali L, Amadori D. A new emergency in oncology: bone metastases in breast cancer patients (Review). Oncol Lett 2013;6:306-10.

4. Brodowicz T, O'Byrne K, Manegold C. Bone matters in lung cancer. Ann Oncol 2012;23:2215-22.

5. Ibrahim T, Farolfi A, Mercatali L, et al. Metastatic bone disease in the era of bone-targeted therapy: clinical impact. Tumori 2013;99:1-9.

6. Coleman RE. Clinical features of metastatic bone disease and risk of skeletal morbidity. Clin Cancer Res 2006;12:6243s-9.

7. Svendsen ML, Gammelager H, Sværke C, et al. Hospital visits among women with skeletal-related events secondary to breast cancer and bone metastases: a nationwide population-based cohort study in Denmark. Clin Epidemiol 2013;5:97-103.

8. Skov Dalgaard K, Gammelager H, Sværke C, et al. Hospital use among patients with lung cancer complicated by bone metastases and skeletal- related events: a population-based cohort study in Denmark. Clin Epidemiol 2015;7:363-8.

9. Nørgaard M, Jensen AØ, Jacobsen JB, et al. Skeletal related events, bone metastasis and survival of prostate cancer: a population based cohort study in Denmark (1999 to 2007). J Urol 2010;184:162-7.

10. Yong M, Jensen AÖ, Jacobsen JB, et al. Survival in breast cancer patients with bone metastases and skeletal-related events: a population-based cohort study in Denmark (1999-2007). Breast Cancer Res Treat 2011;129:495-503.

11. Drzymalski DM, Oh WK, Werner L, et al. Predictors of survival in patients with prostate cancer and spinal metastasis. Presented at the 2009 Joint Spine Section Meeting. Clinical article. J Neurosurg Spine 2010;13:789-94.

12. Yuasa T, Urakami S, Yamamoto S, et al. Treatment outcome and prognostic factors in renal cell cancer patients with bone metastasis. Clin Exp Metastasis 2011;28:405-11.

13. Santini D, Procopio G, Porta C, et al. Natural history of malignant bone disease in renal cancer: final results of an Italian bone metastasis survey. PLoS One 2013;8:e83026.

14. Santoni M, Conti A, Procopio G, et al. Bone metastases in patients with metastatic renal cell carcinoma: are they always associated with poor prognosis? J Exp Clin Cancer Res 2015;34:10.

15. Cetin K, Christiansen CF, Sværke C, et al. Survival in patients with breast cancer with bone metastasis: a Danish population-based cohort study on the prognostic impact of initial stage of disease at breast cancer diagnosis and length of the bone metastasis-free interval. BMJ Open 2015;5:e007702.

16. Cetin $\mathrm{K}$, Christiansen CF, Jacobsen JB, et al. Bone metastasis, skeletal-related events, and mortality in lung cancer patients: a Danish population-based cohort study. Lung Cancer 2014;86:247-54.

17. Santini D, Daniele S, Barni S, et al. Natural history of non-small-cell lung cancer with bone metastases. Sci Rep 2015;5:18670.

18. Gottwald L, Dukowicz A, Piekarski J, et al. Bone metastases from gynaecological epithelial cancers. J Obstet Gynaecol 2012;32:81-6.

19. Schmidt M, Pedersen L, Sørensen HT. The Danish Civil Registration System as a tool in epidemiology. Eur J Epidemiol 2014;29:541-9.

20. Lynge E, Sandegaard JL, Rebolj M. The Danish national patient register. Scand J Public Health 2011;39:30-3.

21. Thygesen SK, Christiansen CF, Christensen S, et al. The predictive value of ICD-10 diagnostic coding used to assess Charlson comorbidity index conditions in the population-based Danish national registry of patients. BMC Med Res Methodol 2011;11:83.

22. Jensen $A \varnothing$, Nørgaard $M$, Yong $M$, et al. Validity of the recorded International Classification of Diseases, 10th edition diagnoses codes of bone metastases and skeletal-related events in breast and prostate cancer patients in the Danish National Registry of Patients. Clin Epidemiol 2009;1:101-8. 